\title{
Cardiovascular pre-participation screening in young athletes: Recommendations of the Association of European Paediatric Cardiology - CORRIGENDUM
}

Peter Fritsch, Robert Dalla Pozza, Doris Ehringer-Schetitska, Eero Jokinen, Vesna Herceg, Erzsebet Hidvegi, Renate Oberhoffer, Andreas Petropoulos, on behalf of the Association for European Paediatric Cardiology Working Group Cardiovascular Prevention

doi:10.1017/S1047951117001305, Published by Cambridge University Press, 9 August 2017.

First published online: 10 January 2018

The authors apologise for the incorrect spelling of one of the author names. This was published as Vesna Herceg, but should have appeared as Vesna Herceg-Cavrak.

\section{Reference}

Peter Fritsch, Robert Dalla Pozza, Doris Ehringer-Schetitska, Eero Jokinen, Vesna Herceg, Erzsebet Hidvegi, Renate Oberhoffer, Andreas Petropoulos, on behalf of the Association for European Paediatric Cardiology Working Group Cardiovascular Prevention. Cardiovascular pre-participation screening in young athletes: Recommendations of the Association of European Paediatric Cardiology. Cardiol Young Published by Cambridge University Press, 9 August 2017. doi: 10.1017/ S1047951117001305. 